\title{
ONZE TWAALFDE PROVINCIE IN NOOD
}

\author{
DOOR
}

\author{
MR. DR. C. F. SCHOCH \\ De Surinaamsche kwestie heeft twee kanten, die \\ men scherp gescheiden moet houden. Voor de Suri- \\ namers alleen bestaat op het oogenblik de kwestie: \\ „hoe houden wij ons boven water"; voor Neder- \\ land en Suriname samen is het groote probleem \\ „hoe maken wij het land, dat stellig de natuurlijke \\ elementen er voor bezit, tot eene kolonie, die zich- \\ zelf bedruipt en daardoor haar eigen zaken zelf \\ regelen kan". \\ van Blankensteyn, blz. 18 van „Suriname”
}

Daar ligt voor ons een goed gedrukt, nieuw boek over onze West-Indische kolonie Suriname. De 339 bladzijden laten zich gemakkelijk lezen en de plaatjes geven aardige kijkjes op land en volk.

Men had ook niet anders kunnen verwachten van een geschrift van den algemeen bekenden en gaarne gelezen ster-correspondent van de Nieuwe Rotterdamsche Courant, Dr. M. van Blankensteyn.

Velen in den lande zullen met belangstelling gevolgd hebben de in den loop van 1923 in de Nieuwe Rotterdamsche courant gepubliceerde artikelen van den heer van Blankensteyn. Van verschillenden kant, zoo deelt de schrijver in zijn voorwoord mede, is er bij hem op aangedrongen zijne reeks artikelen in boekvorm uit te geven. Aan dien wensch heeft schrijver gevolg gegeven en zoo ligt dan daar nu voor ons zijn keurig, bij Nijgh en van Ditmar's Uitgevers Maatschappij te Rotterdam verschenen boek, getiteld „Suriname”.

Ook ik heb behoord tot degenen, die Dr. van Blankensteyn hebben gevraagd om, zooals hij het noemt, door deze populaire publicatie meer blijvend houvast te geven 
aan de gewekte belangstelling, en daarom acht ik het een voorrecht in onze West-Indische Gids eene korte bespreking te wijden aan deze uitgave.

In den loop der jaren hebben reeds herhaaldelijk groote dagbladen in Nederland reeksen artikelen over Suriname in hunne kolommen opgenomen. Ik herinner hier slechts aan de „Surinaamsche brieven", die reeds in het begin van deze eeuw een tijd lang geregeld in het Algemeen Handelsblad verschenen en waarvan de schrijver mij persoonlijk goed bekend is, en ook aan de geregeld in de laatste jaren in „de Standaard” opgenomen artikelen van een sedert gerepatriëerd Surinaamsch ambtenaar, artikelen, die de gemoederen van sommigen in de kolonie dikwijls zeer hebben verontrust.

Maar nog nooit was vertoond, wat Gouverneur van Heemstra uitdacht, om een bekend redacteur van een groot Nederlandsch blad naar Suriname te doen komen met het doel om de aandacht van een grooter deel van het Nederlandsche volk op den toestand der kolonie te vestigen dan mogelijk was met de voortreffelijke rapporten over Suriname van de laatste jaren. Die gedachte van Gouverneur van Heemstra was practisch en juist. De courant dient veel meer dan vroeger tot leidster bij de ontwikkeling van het lezend publiek. Tijdschriftartikelen, verhandelingen, rapporten, hoe goed ook gesteld, bereiken het groote publiek niet zoo zeer en ten aanzien van ons Suriname is het nu eenmaal noodig het publiek eene juiste voorstelling te geven van wat daar geschiedt, omdat het Nederlandsche volk in zijn geheel verantwoordelijk blijft voor de wijze, waarop Suriname tot bloei of tot verval gebracht wordt.

Daarom verdient Gouverneur van Heemstra voor zijne uitnoodiging den lof van alle weldenkenden en de hoofdredactie van de N. R. Courant grooten dank voor het inwilligen van het verzoek.

Deschrijver heeft het probleem, dat hij ging behandelen eerst goed bestudeerd en heeft daarna zijne oogen en ooren ter dege gebruikt, alvorens hij zich ging neerzetten om met zijne welversneden pen het door hem verwerkte aan 
het papier toe te vertrouwen. Natuurlijk heeft Dr. van Blankensteyn reeds meermalen in zijn leven gestaan voor de moeilijkheid om ingewikkelde problemen te ontwarren om dan daarna de zaak tot de kern terug te brengen, waarom het gaat. Maar het baart toch verwondering hoe iemand in zoo korten tijd een juisten blik kan krijgen op het ingewikkelde samenstel van omstandigheden, dat de kolonie Suriname gemaakt heeft tot wat die kolonie thans is.

Niemand zal mij van aanmatiging beschuldigen, wanneer ik, na 31 jaren ervaring in den arbeid voor de kolonie, in verschillende betrekkingen opgedaan, de meening heb, tot oordeelen in deze eenigszins bevoegd te zijn. Gaarne laat ik daarop dan dadelijk volgen, dat ik met groot genoegen en groote instemming, eerst de losse artikelen, en thans weder het boek heb doorgelezen en dat $\mathrm{ik}$, met vol vertrouwen, de lezing van dit werk aan iedereen kan aanbevelen, die een actueel beeld van de kolonie Suriname geteekend wil zien door iemand, die, onbevooroordeeld, zijn kennis en indrukken verzamelde.

Het kan natuurlijk niet de bedoeling van eene bespreking zijn om den schrijver op den voet te volgen.

Het geheele boek is lezenswaard en vertrouwbaar en, heeft men de voorstelling van zaken, zooals Dr. van Blankensteyn die geeft, goed in zich opgenomen, dan heeft de lezer voor zich een vrij juist beeld van den kolonialen toestand.

Op enkele bloot gelegde wondeplekken wil ik nader de aandacht vestigen om daarna het geheele feitenmateriaal te overzien en ook mijnerzijds de conclusies voor heden en toekomst van de kolonie aan te geven.

Ik begin dan met den persoonlijken staat van den Surinamer. In de laatste 30 jaren is met grooten ijver aan de uitbreiding en verbetering van het onderwijs gewerkt - Dr. H. D. Benjamins heeft daarmede als Inspecteur voor het Onderwijs veel bereikt - en voor de Surinaamsche jonglieden is daarmede de wereld als 't ware geopend. Maken zij echter van die geboden gelegenheid gebruik, 
dan valt daar dadelijk een slagboom, die hun het gaan buiten de koloniale grenzen bemoeilijkt. Zij kunnen nl. geen Nederlandsche pas bekomen, want slechts een enkele Surinamer, hoe Nederlandsch hij ook zij, kan bewijzen onder de bepalingen van de wet van 1892 op het Nederlanderschap te vallen. De staat van Nederlander moet bewezen worden door het Nederlanderschap van den vader of, bij erkenning alleen door de moeder, door dat van de moeder. $\mathrm{Nu}$ is die erkenning een groote factor in de Surinaamsche maatschappij, vooral ook, omdat in den loop der jaren weinig rekening is gehouden met de verplichting van eene officieele, afzonderlijke erkenning. Gaat men dus napluizen - en dat gebeurt bij de aanvraag om een pas - dan blijkt zeer dikwijls, dat eene behoorlijke erkenning niet heeft plaats gehad. Men kan zich dan niet behelpen met de voor in Nederland geboren personen geldende bepaling, dat men toch op Nederlandsch grondgebied is geboren, want die plaatsbepaling geldt alleen voor het rijk, d. w. z. het rijk in Europa. Met eene kleine wetswijziging ware dit euvel te verhelpen, door ook degenen, die op Nederlandsch grondgebied in West-Indië zijn geboren den staat van Nederlander toe te kennen.

$\mathrm{Nu}$ ontvangt men een bewijs van in Suriname geboren te zijn, maar voor het in dienst treden als stuurman en machinist of bij leger en marine, om geen andere betrekkingen te noemen, en voor een verblijf in het buitenland is een pas toch een vereischte.

Dr. van Blankensteyn heeft over dit bezwaar zeer duidelijk geschreven op blz. 136 e. v. van zijn boek.

Een tweede groot bezwaar voor de Surinaamsche maatschappij, dat gemakkelijk ware weg te ruimen, is het moeilijke en kostbare telegrafische verkeer. De schrijver handelt daarover op blz. $143 \mathrm{e}$. v. van zijn boek.

Het is onbegrijpelijk, dat de Regeering een dergelijken archaïschen toestand in de kolonie laat voortbestaan. Het is een dagelijks terugkeerende ergernis voor de koloniale maatschappij, die geleerd heeft zıch naar het wereldverkeer te richten, dat de kabel van de „Cie. française des 
cables télégraphiques" groote gedeelten van het jaar onbruikbaar is en de tarieven exorbitant hoog zijn. De Surinaamsche Bank heeft de Regeering reeds jaren geleden op dezen misstand gewezen en ook de West-Indische Kamer te Amsterdam richtte daarover in 1919 een vertoog tot den Minister van Koloniën. Intusschen kwam een particulier draadloos station te Paramaribo in werking, maar dat mag slechts voor het publiek beschikbaar gesteld worden, als de telegraafkabel onbruikbaar is en dan moet nog het ouderwetsche tarief worden betaald voor telegrammen. Van Nederland naar Suriname betaalt men $f 4.12^{1} / 2$ per woord, van Nederland naar de Britsche Koloniën Demerary, Trinidad en Jamaica $f 1.72^{1} / 2$ per woord. Is het wonder, dat de handel in Suriname zijn telegrammen dikwijls eerst naar Georgetown per post verzendt en zoo guldens uitspaart voor ieder telegram?

Waarom de Regeering het telegraafcontract niet laat voor wat het is en eene draadlooze verbinding tot stand brengt, met als steunpunten de bestaande installaties op Curaçao en Martinique, blijft een raadsel. De concessie van de Fransche kabelmaatschappij betreft slechts kabelverbindingen en geen draadlooze verbindingen. De koloniale maatschappij lijdt voortdurende schade door deze stiefmoederlijke zorg.

Nog op een ander bezwaar, ook door Dr. van Blankensteyn genoemd, op blz. 162, vestig ik de aandacht. Een der redacteuren van onze West-Indische Gids is op dit punt een onvermoeid strijder. Ik bedoel het gebrek aan eene behoorlijke regeling ten aanzien van de westelijke grens van de kolonie. $\mathrm{Nu}$ hoe langer hoe meer een drang ontstaat om dat westelijk gedeelte van de kolonie geopend te krijgen voor het onderzoek naar goud, balata en diamanten kan een vrij openstellen van dat deel niet uitblijven. Het ontstaan van een grensgeschil tusschen Nederland en Groot-Brittannië is dan slechts een kwestie van tijd. De vraag van den schrijver aan den Minister van Koloniën, of hij nog even gerust zal zijn, dat de grens- 
kwestie aan de Corantijn ook verder geen moeilijkheden zal opleveren, wanneer in het betrokken gebied diamanten zouden worden gevonden, lijkt mij volkomen gerechtvaardigd.

Ik noemde bovenaangegeven bezwaren het eerst, niet omdat zij de belangrijkste zijn, maar omdat zij zoo gemakkelijk, naar mijne meening, zouden zijn te ondervangen.

De belangrijkste vraag is natuurlijk, als alles waar is, wat Dr. van Blankensteyn ons in zijn boek vertelt en wat hem eenmaal zelfs doet schrijven, dat „Suriname is een bouwval", hoe komen wij dan met de kolonie uit het moeras?

Onder de bezwaren, door den schrijver genoemd, die een opleven van de kolonie zouden tegenhouden, zijn er, die m. i. te hoog worden aangeslagen. Zoo acht ik bv. den invloed van de adviezen door den Administrateur, chef der 10de afdeeling aan het Departement van Koloniën, aan naar Suriname vertrekkende ambtenaren medegegeven, inderdaad te breed uitgemeten. Ik kan mij voorstellen dat de schrijver, die zijn eigen ondervinding mededeelt, ten zeerste ontroerd was, toen hij personen en zaken anders vond dan zij hem waren voorgesteld, maar de nadeelen van eene verkeerde voorstelling verdwijnen spoedig, wanneer men, eenmaal in de kolonie aangekomen, uit eigen oogen gaat zien. Slechts een paar personen, heb ik in al die jaren in de kolonie onder de Nederlandsche ambtenaren ontmoet, die daar zich niet thuis gevoelden en spijt hadden naar de kolonie te zijn gekomen. Bovendien, als men denkt over een gaan naar de kolonie, steekt men zijn licht toch niet uitsluitend op aan de officieele bron. I k heb vele malen menschen, die in deze richtıng plannen maakten, met advies kunnen dienen.

Evenmin kan ik zoo belangrijk achten voor het welzijn van de kolonie de kwestie of er door de Regeering minder directen invloed moet worden uitgeoefend op het bestuur van de kolonie. Ik weet, dat ik hier iets neerschrijf, dat niet iedereen, vooral niet iedereen in de kolonie, als juist zal onderschrijven. Maar ik vraag: als de cultures in de 
kolonie bloeiden en als gevolg daarvan de handel opleefde en de opbrengst van de koloniale middelen steeg en het aan de kolonie thans gegeven subsidie, in plaats van voortdurend hooger te worden, een dalende lijn vertoonde zou dan het bezwaar van een medespreken in den Haag bij den te volgen bestuursweg zoo zeer gevoeld worden? Immers neen. De welvaart van de kolonie hangt niet af van het iets meer of minder uitgeven voor straten- of riolenverbetering, voor verbetering van de huisvesting of voor verhooging van de ambtenaarssalarissen. Het prikkelt natuurlijk, wanneer kleine maatregelen in den Haag niet goedgekeurd worden, die men te Paramaribo noodig vindt, en de arbeidsvreugde kan daardoor in de kolonie worden verstoord en de harmonische samenwerking tusschen Regeering en Bestuur kan daardoor worden bedreigd. Ik herinner aan dergelijke wezenlijke of dreigende conflicten tusschen verschillende Gouverneurs als Jhr. van Asch van Wijck, Mr. Tonckens, Baron van Asbeck, den heer Staal en Baron van Heemstra en de tijdens hun bestuur fungeerende Ministers van Koloniën. Maar de groote economische lijn van ontwikkeling of aftakeling beweegt zich los van dergelijke incidenten. En soms kan het rustig, bezonken oordeel van personen, in de gematigde luchtstreek levende, nog wel eens weldadigen invloed uitoefenen op lievelingsdenkbeelden van met vele goede bedoelingen, nieuw opgetreden landvoogden. Die ervaring kan ook ieder buiten de bestuurskringen opdoen. Ik onderschat de beteekenis van aangename, eensgezinde samenwerking geenszins, en evenmin die van de noodige vrijheid van handelen in het gebied over zee, maar ik acht die niet van primair belang, wanneer het, zooals thans met Suriname, gaat om het wel of wee der kolonie. Dit laatste is wèl het geval met de bestrijding van de mijnwormziekte en een afwijzen van de gevraagde f 3000.- - dienende tot behoud van het door de Rockefeller foundation verkregene, ware m.i. onverantwoordelijk geweest.

Gaarne geef ik, desgewenscht, mijne meening over die begeerde autonomie van het Koloniaal Bestuur, maar 
niet thans, nu het gaat om de hoogste belangen van de kolonie.

Zoo kan ik ook, tot mijn spijt, niet die waarde toekennen aan het bezit van goede verkeerswegen te land in de kolonie, die de Gouverneurs van Asbeck en Staal daaraan hebben gehecht en nu ook Dr. van Blankensteyn ziet (blz. 146).

Het water vormt in Suriname den natuurlijken verkeersweg. Zeker, die verkeersweg vordert tijd, maar tijd is iets, waaraan het een Surinaamsch ingezetene in den regel het minst ontbreekt. Verkeerde de kolonie in bloeienden staat, dan zouden de belanghebbenden bij zoo'n verkeersweg te land de handen wel in een slaan, zooals dat indertijd met den rijweg langs de Commewijne het geval was en het Koloniaal Bestuur zou dan regelend en helpend kunnen optreden. Maar is dat belang voor de omwonenden niet zoo groot, dat zij daarvoor in den buidel tasten, niet eenmaal voor den aanleg, maar voortdurend voor het onderhoud, dan dient met dien aanleg nog gewacht. Ik herinner mij hoe op een gegeven tijdstip, op het einde van de vorige eeuw, men langs den geheelen linkeroever van de Beneden-Saramacca kon loopen. Alles was in orde en de noodige bruggetjes waren over de in de rivier uitmondende kreeken gelegd. Die ideaaltoestand van dubbelen verkeersweg te land en te water, bleef dan ook niet lang volmaakt. Het onderhoud weegt te zwaar, als de belanghebbenden dit niet op zich nemen en zich aan hunne belofte houden. Heeft men van de plantage zware productenvrachten te vervoeren, dan is er geen beter vervoermiddel dan de pont. Een weg zou te veel te lijden hebben onder het gewicht. En willen de kleine landbouwers de stad bereiken, zij doen dat in hun eigen vaartuigje, vlug of langzaam al naar zij verkiezen en het getij het hun veroorlooft. Natuurlijk is het interessant om, zooals ik het voorrecht had, een Britsch-Indiër of Javaan in zijn nationale kleeding zich snel op een fiets langs de rivier te zien voortbewegen en voor den belanghebbende is dat ook een groot gemak, maar het wel of wee van de kolonie - en daarom gaat het in dezen tijd - is daarmede niet gemoeid. 
Maar, zoo zal de lezer wellicht vragen, wat acht schrijver dezes dan wèl van primair belang voor de kolonie om haar in staat te stellen zich weder uit haren gedrukten toestand op te heffen? Kan zelfs nog de hoop gekoesterd worden dat er van de kolonie ooit iets goeds terecht komt? Om die vraag te kunnen beantwoorden, dient eerst zoo zuiver mogelijk de diagnose van de ziekte te worden gesteld, om daarna over de geneeswijze te kunnen handelen.

Hoe komt de kolonie ziek? En wat hebben de in den loop der jaren aan de patiente toegediende geneesmiddelen uitgewerkt? Zou het misschien waar zijn, wat Dr. van Blankensteyn op blz. 216 van zijn boek neerschrijft en reeds gedurende verschillende generaties is gehoord, dat Suriname nu eenmaal door het ongeluk wordt vervolgd en vooral veelbelovende dingen er aan allerlei plagen onderworpen zijn?

Suriname lijdt aan eene verouderde kwaal. De ziekte is over de kolonie gekomen in de eerste helft van de vorige eeuw, toen de slavenhandel werd opgeheven en niet voldoende werd gezorgd voor de noodige aanvulling van den arbeidersstand.

Die ziekte werd acuut, toen in 1863 bij de afschaffing van de slavernij niet de noodige maatregelen werden getroffen om de weldra vrijkomende en natuurlijk toen van geregelden arbeid afkeerige arbeidersmacht door aanvoer van andere arbeiders te vervangen. De Chineezenaanvoer bleek een failure, evenals die van Madeirianen. Wel heeft de aanvoer van Britsch-Indische contractanten het kwaad bedwongen en voor de kolonie eene goede oplossing gebracht, maar de ziekte bleef latent, want de aangevoerde bevolking ging slechts in geringe mate tot vestiging over en alles moest komen van den zoogenaamden grooten landbouw, de cultuur van stapelproducten door de plantages, en het resultaat van dien landbouw hing af van twee groote wisselvallige factoren: de wereldmarktprijzen van suiker, cacao en koffie en het al of niet voorkomen van ziekten in die cultuur-producten.

In het laatste decennium van de vorige eeuw vertoonde 
alles in de kolonie eene stijgende lijn. De cultures gaven ruim bevrediging. Goud en balata werden in steeds ruimere mate gewonnen. De Javanen-immigratie kreeg een vasten grondslag en de Britsch-Indische bevolking ging langzaam aan tot vestiging over op daarvoor speciaal ingerichte vestigingsplaatsen of wel op eigen gekozen terreinen aan de oevers van de groote rivieren. Het Rijkssubsidie ging omlaag en daalde één jaar zelfs tot ongeveer een halve ton.

In dien tijd werd eenerzijds door de Nederlandsche Regeering ten opzichte van de landbouwkolonie een groote fout begaan en anderzijds door de planters roekeloos ten opzichte van de toekomst geleefd. De dringende vraag van Gouverneur van Asch van Wijck om een behoorlijken cultuurtuin te mogen inrichten, waar de plantenziekten zouden worden onderzocht en de middelen tot verbetering van de cultuurgewassen konden worden bestudeerd, vond geen gunstig onthaal in den Haag. $\mathrm{Nu}$ ja, men mocht dan wel een terrein aankoopen om dat tot cultuurtuin in te richten, maar de gelden voor deskundige leiding en aanstelling van wetenschappelijk ontwikkeld personeel werden niet toegestaan. Uit het goed bedoelde plan kwam een klein soort plantentuin te voorschijn, waarin gesukkeld werd met slechte afwatering en groote gedeelten ongeschikt bleken voor cultuur.

En de planters hunnerzijds dachten over het algemeen niet aan den dag van morgen, leefden ruim en verzuimden reserves te maken, dachten er ook niet aan om coöperatief op te treden en op de wijze, zooals later is geschied met het Selectiefonds, waarvan thans Dr. G. Stahel de voortreffelijke leider is, eene instelling in het leven te roepen in navolging van de vele in Ned.-Indië bestaande, ter bestudeering van gewassen en hunne ziekten.

Alles ging goed, men kende uit de praktijk zijne cultures. Waarom zou men geld uitgeven voor al dat in theorie zeer mooie onderzoek ? Zoo werd van Regeeringswege gezegd en van planterswege gedacht.... tot het te laat was.

In het laatst der negentiger jaren begonnen de wereldkoffieprijzen enorm te dalen. Ik herinner mij hoe de prach- 
tige plantage Voorburg, aan de Suriname-rivier gelegen, plotseling voor al hare koffie geen behoorlijken prijs meer kon maken, en, speculeerende op mogelijke verbetering, de koffie op de plantagezolders liet liggen. Men werd toen bedacht op grootere voorzichtigheid bij het leggen van alle risico op ééne cultuur.

De cacaoproductie bleef echter schitterend en 1899 werd een recordjaar met mooie prijzen. Na dit jaar kwam echter een zeer droog jaar en de oude door zware dracht uitgeputte cacaoboonen konden zich niet herstellen. Wat reeds sporadisch in de beplantingen voorkwam, - de toen malige directeur van plantage de Morgenstond verklaarde mij zeer beslist, dat hij die ziekte reeds jarenlang sporadisch in de beplantingen was tegengekomen - ging toen aan het overwoekeren en de geduchte krullotenziekte deed eene ziekteperiode ontstaan, zoo geweldig als in de kolonie nog nooit vertoond was. Geen wonder, dat de planters den moed verloren. Een nu eerst te hulp geroepen deskundige, de eerste directeur van den landbouw, Dr. C. J. J. van Hall, die nog nooit in de tropen was geweest, stond natuurlijk aanvankelijk geheel vreemd tegenover de ziekte en beijverde zich om de oorzaak te zoeken en eene bestrijding te vinden. Levendig herinner ik mij hoe een planter den aanblik van zijne plantage noemde „een wintergezicht", want bijna alles was kaal of zwart geworden.

Was hier nu sprake van een noodlot of ongeluk, dat de kolonie vervolgt of van nalatigheid bij Regeering en Bestuur en belanghebbenden om vooruit te zien en zich in deze onvolmaakte wereld paraat te houden?

Toen kwam Gouverneur Lely, als een redder in den nood, met zijn lumineus bacovenplan. In Suriname zijn allerlei soorten van de Musa inheemsch. Een aanplant in het groot voor export zou de gevallen kolonie weder op de been helpen. Een onderzoek werd op Jamaïca ingesteld, en met de hulp van de machtige United Fruit Company werd op 3000 H.A., over de kolonie verspreid, eene nieuwe, uit Jamaïca ingevoerde, Musasoort, de Gros Michel, in het groot aangeplant. Aanvankelijk ging alles schitte- 
rend en men zag reeds de gouden bergen. De verschepingen stegen van 219.663 bossen in 1908 tot 648.636 in 1909 en 654.162 in 1910.

Eén ding had men echter vergeten. Men had niet voldoende onderzocht of die nieuwe Musasoort wel kon aarden in den haar vreemden grond en in het haar vreemde klimaat. De tijd van proefnemingen was veel te kort geweest en toen de vreeselijke Panamaziekte uitbrak, was het spoedig met het leven van alle Gros Michelplanten gedaan. Ik vergeet nooit den indruk, dien de uitgestrekte terreinen vol doode of doodzieke Gros Michelplanten bij mijn bezoek aan de kolonie in 1910/11 op mij maakten. Door de aanvaarding van de conclusies van een destijds zeer bestreden rapport van eenige vooraanstaande mannen in Nederland van den kant van den Minister de Waal Malefijt en door een tragische vergissing in de kolonie omtrent het voorkomen van de gevreesde ziekte in eene andere Musasoort, de Congobacoven, is toen de bacovenexport en dus ook de verdere bacovenaanplant stopgezet. Achteraf bezien is dat een jammerlijke maatregel geweest.

Maar ik herhaal de vraag: Kan men, als men deze mislukking in het juiste licht van de omstandigheden beziet, spreken van een noodlot of ongeluk, dat de kolonie vervolgt? Of ligt de schuld bij verkeerd genomen maatregelen?

De koloniale geschiedenis van de laatste 12 jaren geeft in het algemeen het beeld van een strijd om het bestaan, van een streven om te behouden wat men had en dat te verbeteren. Nieuwe plannen om de kolonie uit haren zieken toestand op te heffen, werden in groote verscheidenheid beraamd, maar niet uitgevoerd. In het archief van het Ministerie van Koloniën is een aanzienlijk depot van dergelijke plannen en adviezen en rapporten. Intusschen deed men in de kolonie wat men kon. Het allengs met enkele deskundigen versterkt landbouwdepartement droeg er het zijne toe bij en leidde den arbeid; de verschillende ziekten in de cacao werden bestreden, voor een groot deel met succes; toen de koffieprijzen beter werden, 
breidde de koffieaanplant zich aanzienlijk uit, zoodat de uitvoerlijn van dat product eene merkwaardige stijging vertoont en van 1910-1922 van niets gekomen is op 2.165.925 K.G.; de rijstcultuur kreeg in de oorlogsjaren een geweldigen stoot vooruit, zoodat er zelfs gedacht kon worden aan geregelden export;

de sinasaappelcultuur breidde zich rustig uit in afwachting van de zoo zeer gewenschte verschepingsgelegenheid, die op den duur toch niet kan uitblijven; en de bacoventeelt hield men overal zoo'n beetje aan in verband met nieuwe plannen tot aanplant en export in het groot, die nog maar niet tot uitvoering kunnen komen.

Maar daar kwam te midden van die pogingen, om te roeien met de riemen, die men had, de wereldoorlog. Het scheepvaartverkeer hield op en de kolonie werd van de buitenwereld bijna geheel afgesloten.

En toen die storm ook over de kolonie was heengegaan, kwamen de naoorlogsweeën. Duitschland en Oostenrijk moesten uitgeschakeld worden met hun geheele achterland, als koopers van Surinaamsche koffie en cacao en de Scandinavische rijken consumeeren sedert den oor$\log$ duurdere, nl. Braziliaansche koffie, omdat men het daar betalen kan. En de cacao vond op de Amerikaansche markt een steeds grooter wordende concurrent in de Akkracacao uit Midden-Afrika. De prijzen daalden zeer sterk en kwamen beneden de productiekosten, die zelve natuurlijk door verhooging van loonen en het duurder worden van de benoodigde materialen gestegen waren.

Door een en ander is de kolonie wel gekomen op den bodem van de put. Maar ook deze ellende draagt de kolonie niet alléén als ware zij een gevolg van een noodlot of ongeluk. Zij draagt mede, wat de geheele wereld draagt. Alleen haar weerstandsvermogen is geringer. En daardoor kan zij b.v. niet met Nederland zorgen voor de veiligstelling van den gulden. De Surinaamsche gulden is sedert drie jaar niet meer gelijkwaardig aan den Nederlandschen gulden. De waarde van den uitvoer kon zich, door bovengenoemde prijsdaling, niet op gelijke hoogte 
handhaven met de waarde van den invoer, zooals in de voorafgaande jaren de normale toestand was geweest. In 1919 was de waarde van den uitvoer nog $f$ 8,987.870.tegen $f$ 8,946.144.- aan invoer.

In 1920 verhielden die bedragen zich als $f 7,447.512$.tot $f 13,718.026$. - . In 1921 was de verhouding $f 6,562.140$ en $f 13,150.025$. - en in $1922 f 5,688.370$ - en $f$ 10,563.579.- - Met die cijfers voor oogen baart het geen verwondering, dat de vraag naar wissels op het buitenland in de kolonie buitengewoon toenam en dat, waar daartegenover voldoende aanbod van wissel ontbrak, dus de wisselkoersen moesten stijgen. De Surinaamsche Bank deed wat zij kon om die verhooging zoo lang mogelijk tegen te houden, maar geheel tegenhouden kon zij die niet, zoodat de Nederlandsche gulden op 't oogenblik in de kolonie gelijk staat met 106 Surinaamsche guldens. En met de wisselkoersenbeweging steeg ook het rentetype van uitgeleend geld. Ook hierdoor werd de levensstandaard in de kolonie de laatste jaren duurder.

De toestand, waarin de kolonie thans verkeert, is dus het gevolg van tweeërlei kwalen.

Aan den eenen kant lijdt de kolonie aan de, zooals ik het reeds noemde, verouderde kwaal van uitputting en verslapping, doordat in den loop der jaren te weinig gedaan is om nieuw bloed te vormen, door bevordering van de immigratie eenerzijds en, naast krachtig behoud van de bestaande cultures, door het in het leven roepen van nieuwe cultures anderzijds.

En daarmede gaat de kolonie gebukt onder de gevolgen van de algemeene wereldmalaise, waardoor van hetgeen door de kolonie nog kan worden geproduceerd, de opbrengst zoo gering is, dat de gemaakte kosten niet of bijna niet kunnen worden gedekt.

Laat men dien toestand voortbestaan, dan is het noodzakelijk, logisch gevolg, dat plantage na plantage moet worden stopgezet, zooals thans reeds met verscheidene het geval is geweest (in mijn verslag van De Surinaamsche Bank over 1921 gaf ik reeds eene lijst van dergelijke plantages); dat de koloniale inkomsten nog sterker ver- 
minderen; dat de koloniale uitgaven nog zullen stijgen door de zorg voor immigranten en armlastigen en dat ten slotte de kolonie wordt, wat Dr. van Blankensteijn zich liet ontvallen, een bouwval.

Maar gelukkig, wij zijn zoover met de kolonie nog niet. Het land blijft een land van onbegrensde mogelijkheden. Om dat te constateeren, moet men het land slechts leeren kennen. Het is absoluut niet eene uiting van optimisme of idealisme, als ik zoo iets, zelfs nu nog, neerschrijf.

Reeds te lang echter wordt de alarmklok geluid en de Regeering blijft toeven en talmen. Het is inderdaad geen tijd om af te wachten wat particulieren in deze zullen doen en dan wel achterna aan dergelijke pogingen misschien hulp te willen toezeggen. Particuliere ondernemingen zullen niets beginnen als de Regeering niet voorgaat en haar geloof toont in de mogelijkheid van verbetering, door op allerlei wijze het pad voor dat particuliere ondernemen te effenen.

$\mathrm{Bij}$ de overweging van hetgeen dan wèl gedaan zou kunnen worden, dient echter nog één punt op den voorgrond geplaatst te worden. De kolonie heeft nl. in de laatste 15 à 20 jaren economisch eene groote verandering ondergaan. Meende men vroeger, dat het belang van de kolonie uitsluitend gelegen was in de bevordering van den grooten landbouw, dat is thans gelukkig anders geworden. Wij hebben in de kolonie een belangrijken klein landbouwersstand gekregen uit de vroegere vreemde contractarbeiders en die kleine landbouwers, waarvan sommigen door noeste vlijt, zich zelfs tot plantage-eigenaren hebben opgewerkt, kunnen heel wat tot stand brengen, waardoor de kolonie er economisch weder bovenop zou kunnen komen. Met hulp en leiding van het Koloniaal Gouvernement kan overal een bloeiende toestand verkregen worden, als thans in Nickerie bestaat, waar uitgestrekte rijstvelden - een lust voor het oog - de plaats hebben ingenomen van wat een twintigtal jaren geleden nog nietswaardige moerassige boschterreinen waren.

Met dien nieuwen factor dient ter dege rekening ge- 
houden te worden, wanneer men zich beraadt omtrent hetgeen voor de kolonie gedaan moet worden.

Wat zou nu gedaan kunnen worden binnen de grenzen der bestaande mogelijkheden, dus met inachtneming van de groote bezuiniging, die thans in Nederland moet worden doorgevoerd?

In de eerste plaats moet behouden worden, wat er in de kolonie nog is. Aan de cultuurondernemingen moet het voortbestaan worden mogelijk gemaakt. Die mogelijkheid bestaat op het oogenblik slechts voor zeer weinige ondernemingen. De algemeene kosten drukken thans te zwaar op het product. De immigratie bv. is een landsbelang, omdat bevolkingsvermeerdering een landsbelang is. Die immigranten moeten zich aanpassen aan het nieuwe klimaat, aan de nieuwe omgeving; moeten leeren hun handen te gebruiken bij den landarbeid, zoo geheel verschillend van die in het land van herkomst.

Dat alles neemt tijd en alles wat zij in dien leertijd en aanpassingstijd aan kennis en ervaring opdoen, komt na den vijfjarigen contracttijd ten voordeele van de koloniale maatschappij, want dan zijn die menschen geschikt geworden om als kolonist zich te vestigen en dragen bij in het maatschappelijk inkomen, zooals de oud Agent-Generaal, C. van Drimmelen, eenige jaren geleden met cijfers vastlegde. De vraag, onlangs tot den Minister van Koloniën gericht, door de in Nederland wonende plantageeigenaars om ontheven te worden van de betaling van aanvoerkosten, zooals die thans gevorderd wordt naar reden van 15 cent per werkdag, acht ik om de bovenaangegeven reden geenszins onbillijk. En daarnaast kunnen de cultuurondernemingen ontlast worden van allerlei drukkende en geldkostende bepalingen, indertijd ons opgelegd door de Britsche Regeering toen de kolonie nog BritschIndische contractarbeiders mocht importeeren. Het zou mij te ver voeren om hierover uit te wijden, maar o.a. de plantagehospitaalregeling zou door centralisatie veel economischer kunnen geregeld worden.

De vergoeding voor den geneeskundigen dienst in de 
districten zou ook minder drukkend gemaakt kunnen worden en de door het Koloniaal Bestuur opgelegde loonminima zouden weder moeten worden losgelaten.

Executie van plantages om belastingschuld zou ook, in het algemeen belang, in dezen tijd voorkomen moeten worden. Nog in dit jaar trok de West-Indische Cultuurbank zich van het verder financieren van eene onderneming plotseling terug en verloor daardoor het geleende geld, omdat eene dergelijke executie aanstaande was en dus voortzetting van de cultuur op den bestaanden voet onmogelijk zou worden.

Door verlichting van lasten kan van Gouvernementswege de mogelijkheid voor de bestaande cultuurondernemingen worden geschapen om den algemeenen malaisetijd door te komen en den beteren tijd af te wachten. De gevolgen van de tweede oorzaak der Surinaamsche ziekte worden dan zooveel mogelijk beperkt. Trouwens, als de bestaande cultuurondernemingen weder op adem kunnen komen, zullen allicht nieuwe combinaties bereid gevonden worden om in de kolonie de cultuur van stapelproducten uit te breiden. Op die wijze wordt dan weder de immigrantenbevolking uitgebreid en het algemeen koloniaal belang gediend.

Naast dit behouden van wat nog bestaat, dient beslist eene nieuwe cultuur te worden aangevat, die ook door den klein landbouwersstand kan worden ter hand genomen. Koffie en cacao eischen als meerjarige cultures te veel kapitaal, en dus uithoudingsvermogen voor die kleine luiden. Over suikerriet-aanplant zwijg ik maar. Die zou slechts in het groot mogelijk zijn als er meerdere centraalfabrieken waren, die het riet zouden willen opkoopen. Zoo ver is het nog lang niet en wij moeten bij den bestaanden desolaten toestand ons bepalen bij hetgeen dadelijk zou kunnen worden aangevat.

De bacovencultuur is de cultuur, waarop de geheele kolonie wacht. Maar de menschen, die deze zaak willen aanpakken missen werkkapitaal en vragen voorschot. In mijn verslag van De Surinaamsche Bank over 1922 heb ik met aandrang de noodzakelijkheid bepleit, dat de Regee- 
ring hier de helpende hand zou bieden. Ik meen niet beter te kunnen doen dan hier over te nemen, wat ik begin Mei 1923 daarover schreef: „Nederland zal als koloniaal rijk, overeenkomstig zijn stand als zoodanig, zijn twaalfde provincie over zee, de krachtige en gevulde hand moeten reiken. Niet om de bestaande cultures van den ondergang te redden; zoodra op de wereldmarkt de reserves uitgeput zijn en koffie en cacao weder in meerdere mate gevraagd worden, zullen die cultures, waaraan men thans in de kolonie, door selectie en zorgvuldiger bereiding van het product meerdere zorg is gaan besteden dan vroeger, zeker wel weder voordeel afwerpen. Nederland zal practische en profijtelijke hulp kunnen verleenen, indien zoowel groote landbouw als kleine landbouw, beide geholpen worden bij het tot stand komen van eene nieuwe éénjarige cultuur, nl. de bacovencultuur. Ten aanzien van de mogelijkheden van die cultuur zijn in de laatste jaren, zoowel wetenschappelijk als practisch, verschillende proefnemingen en onderzoekingen gedaan en men mag aannemen, dat ten deze succes te verkrijgen is, wanneer eenerzijds de nervus rerum, een aanvankelijk benoodigd werkkapitaal, verkregen kan worden en anderzijds van degenen, die het vervoer wel op zich zouden willen nemen, het risico eenigszins wordt afgenomen.

„Het Koloniaal Bestuur ziet in die richting ook eene heilzame oplossing, want bij zijne begrootingsvoorstellen voor 1924 heeft de Gouverneur $f$ 20.000.- uitgetrokken voor uitbreiding van de Gouvernements-koffieplantage Slootwijk met 50 H.A. Als toelichting schrijft de Gouverneur daarbij: „,Met te meer nadruk wordt deze uitbreiding „(van den koffieaanplant) voorgesteld, aangezien zij dienst„baar kan worden gemaakt aan de deelname in aanplan„ting van bacoven voor den uitvoer en daarmee ook nauw „verband houdt. Waar de ondergeteekende verwacht, dat „van particuliere zijde eene bevredigende oppervlakte „met bacoven beplant zal worden, meent hij, dat het Gou„vernement van zijn groote belangsteling in dien uitvoer „moet doen blijken, door zelf flink daaraan deel te nemen. „Daar de bacoven tevens als hulpschaduw voor de jonge 
„koffieplanten dienst doen, wordt deze aanplant op die „wijze tevens gemakkelijk uitgebreid.”

„Het gaat hier niet om iets nieuws, na zoovele mislukkingen in andere richting; het gaat om de voortzetting van eene cultuur, die reeds onder het bestuur van Gouverneur Lely in het begin dezer eeuw werd ondernomen, maar toen, omdat de uitgekozen bacovensoort voor den aanplant in het groot niet deugde, of wel, omdat de wijze van aanplant verkeerd bleek, moest worden losgelaten.

„Het gaat hier alleen om het in gang zetten van die nieuwe cultuur op de wijze zooals een paar jaar geleden werd beproefd de koffieondernemingen door tusschenkomst van de West-Indische Cultuurbank te steunen met voorschotten.

„Daarmede zou naar eene benoodigde cultuuroppervlakte van 600 H.A. volgens de in de kolonie gemaakte berekeningen, gemoeid zijn een bedrag van nog geen $f 600.000$. - en wel voor aanleg $f 400$. - per H.A. en voor onderhuod gedurende $1 \frac{1}{4}$ jaar per H.A. $f 500$.- , samen $f$ 540.000.-.

„Daarnaast zouden dan de bezwaren, die bij hen, die zich voor het transport willen interesseeren, zwaar wegen, eenigszins uit den weg geruimd kunnen worden.

„Deze bezwaren betreffen het risico van de foutvracht, d.w.z. dat er soms minder vruchten zouden geleverd worden dan overeengekomen, en daarnaast het risico, dat de vrachtkosten wellicht te hoog zouden blijven tegenover de opbrengst der vruchten en de vruchtenkoopers voor verlies bij deze proef zouden wenschen gevrijwaard te worden.

„In het allerongunstigste geval zouden, volgens de daarvan gemaakte berekeningen, beide risico's eene $\mathrm{Re}-$ geeringsgarantie vereischen van $f$ 1.350.000.-

"In totaal zou dus met deze onderneming ongeveer $f$ 2.000.000. - gemoeid zijn. Slaagt de proef, dan zouden de voorgeschoten $f 600.000$. - weder spoedig afbetaald zijn, terwijl de garantie voor foutvracht enz. in de praktijk, door daarvoor te maken regelingen, weinig bezwaar 
zou opleveren. Mijn bestek voorlooft mij niet om hierover uitvoeriger uit te wijden."

Nader vernam ik, dat zelfs de genoemde $f 600.000$ niet door de Regeering zouden behoeven te worden uitgegeven, daar de directie van eene mij bekende instelling het voorstel zou gedaan hebben dat geld voor te schieten, mits de Regeering zich garant zou stellen voor de terugbetaling.

Wij hebben hier te doen met een van die vicieuze kringetjes, waarover Dr. Blankensteyn ook schrijft. Wie zal moeten beginnen? de planter zonder zekerheid van vervoer van zijne bacoven te zijner tijd, of moet de verscheper eerst de zekerheid geven van vervoergelegenheid vóórdat de planter gaat planten! Mij dunkt, zooals ik boven aangaf, de Regeering kan beide partijen zonder groot financieel risico tevreden stellen en dus de zaak aan het rollen brengen. Dergelijke garantieverleening is voor de Regeering geen onbekende zaak. Dat zou met verschillende voorbeelden zijn te staven.

Hetzelfde geldt van de sinaasappelenteelt en -uitvoer. Voor deze cultuur wordt niet eens geld gevraagd, alleen geschikte verschepingsgelegenheid met koelruimten. De sinaasappelaanplant is reeds voor een deel in de kolonie aanwezig. Veredeling van de citrussoorten is, onder de leiding van Dr. G. Stahel, slechts een kwestie van tijd. Ook in deze aangelegenheid zou Regeering en Koloniaal Gouvernement de zaak over het doode punt heen kunnen halen. De producenten zouden gaarne leveren en de vruchtenimporteurs in Nederland zouden willen koopen. De moeilijkheid blijft echter gelegen in eene goede verschepingsgelegenheid met koelruimte. Die moeilijkheid zou tegelijk met de regeling van den bacovenuitvoer in orde komen.

$\mathrm{Na}$ dit neergeschreven te hebben, zie ik in gedachte deze twee nieuwe cultures met de rijstcultuur als derde de kolonie weder in groote actie brengen. De geheele kleinlandbouwersstand zal zich op deze cultures gaan toeleggen; ook de groote cultuurondernemingen zullen een deel van hun tot nog toe niet ontgonnen land voor deze cultu- 
res geschikt gaan maken en daarnaast zullen de plantagedirecteuren, die intusschen weder levensmoed en arbeidslust hebben gekregen, hunne stapelproducten verbeteren, zoodat men in Europa b.v. de Surinaamsche Liberia niet meer als minderwaardig dan de Indische Liberia zal durven qualificeeren. Het economisch evenwicht zal dan in de kolonie weder worden hersteld en de handel zal opleven.

Met voordacht vraag ik hier nu niet de aandacht van den lezer voor de bauxietwinning en de goud- en balataindustrie, voor het ijzererts van den Donderbari en voor de mogelijke diamantvondsten, omdat een en ander slechts als accessoria dienen beschouwd te worden in eene landbouwkolonie, zooals Suriname is.

En wellicht ware er, om nu in dezen bezuinigingstijd niet uit den toon te vallen, ook nog wel hier en daar op de tegenwoordige uitgaven der kolonie te besparen, maar daarover te schrijven valt mij misschien een andere maal nog wel eens gemakkelijk.

Alleen wil ik hier reeds eene mogelijke verhooging der inkomsten aangeven. Het heeft mij altijd als een bepaalde fout toegeschenen, dat in 1899 het zoogenaamde hoofdgeld is afgeschaft. Ieder ingezetene der kolonie betaalde tot dien tijd krachtens de door Gouverneur Mr. J. H. Smidt vastgestelde verordening van 9 Februari 1886, f 6.- als minimum aan personeele belasting als het een man en f3.- als het een vrouw gold. Nu betalen van de \pm 115.000 ingezetenen slechts 1598 eenige directe belasting. De anderen behoeven niets te betalen voor al de voordeelen, die zij van de koloniale samenleving trekken. Dat acht ik in hooge mate onbillijk en eene benadeeling van de koloniale kas met ongeveer een half millioen.

Bevolkingsaanwas blijft natuurlijk een eerste eisch, maar, om die met succes aan te vatten, moet eerst gelegenheid verschaft worden om in levensonderhoud te kunnen voorzien; dus moet een voor den landbouwer gemakkelijk en profijtelijk te behandelen cultuur in het leven geroepen worden. 
518 ONZE TWAALFDE PROVINCIE IN NOOD

Daarom gaat het op het oogenblik. Ik beaam de slotwoorden van de voorrede van Dr. van Blankensteyn ten volle: Uitstel levert gevaar op” en eindig als hij: „Caveant consules".

Amsterdam, 8 December 1923 